\title{
Multi-scale spatial relationships between soil total nitrogen and influencing factors in a basin landscape based on multivariate empirical mode decomposition
}

\author{
ZHU Hongfen ${ }^{1,2,3}$, CAO Yi $^{1}$, JING Yaodong ${ }^{1,2}$, LIU Geng ${ }^{4}$, BI Rutian ${ }^{1,2^{*}}$, YANG Wude ${ }^{3}$ \\ ${ }^{1}$ College of Resource and Environment, Shanxi Agricultural University, Taigu 030801, China; \\ ${ }^{2}$ National Experimental Teaching Demonstration Center for Agricultural Resources and Environment, Shanxi Agricultural \\ University, Taigu 030801, China; \\ ${ }^{3}$ College of Agriculture, Shanxi Agricultural University, Taigu 030801, China; \\ ${ }^{4}$ Research Center for Scientific Development in Fenhe River Valley, Taiyuan Normal University, Jinzhong 030619, China
}

\begin{abstract}
The relationships between soil total nitrogen (STN) and influencing factors are scale-dependent. The objective of this study was to identify the multi-scale spatial relationships of STN with selected environmental factors (elevation, slope and topographic wetness index), intrinsic soil factors (soil bulk density, sand content, silt content, and clay content) and combined environmental factors (including the first two principal components (PC1 and PC2) of the Vis-NIR soil spectra) along three sampling transects located at the upstream, midstream and downstream of Taiyuan Basin on the Chinese Loess Plateau. We separated the multivariate data series of STN and influencing factors at each transect into six intrinsic mode functions (IMFs) and one residue by multivariate empirical mode decomposition (MEMD). Meanwhile, we obtained the predicted equations of STN based on MEMD by stepwise multiple linear regression (SMLR). The results indicated that the dominant scales of explained variance in STN were at scale $995 \mathrm{~m}$ for transect 1, at scales 956 and $8852 \mathrm{~m}$ for transect 2, and at scales 972,5716 and 12,317 $\mathrm{m}$ for transect 3. Multi-scale correlation coefficients between STN and influencing factors were less significant in transect 3 than in transects 1 and 2. The goodness of fit root mean square error (RMSE), normalized root mean square error (NRMSE), and coefficient of determination $\left(R^{2}\right)$ indicated that the prediction of STN at the sampling scale by summing all of the predicted IMFs and residue was more accurate than that by SMLR directly. Therefore, the multi-scale method of MEMD has a good potential in characterizing the multi-scale spatial relationships between STN and influencing factors at the basin landscape scale.
\end{abstract}

Keywords: intrinsic mode function; multivariate empirical mode decomposition; multi-scale spatial relationship; sampling transect; soil total nitrogen; Chinese Loess Plateau

Citation: ZHU Hongfen, CAO Yi, JING Yaodong, LIU Geng, BI Rutian, YANG Wude. 2019. Multi-scale spatial relationships between soil total nitrogen and influencing factors in a basin landscape based on multivariate empirical mode decomposition. Journal of Arid Land, 11(3): 385-399. https://doi.org/10.1007/s40333-019-0054-1

\section{Introduction}

Soil total nitrogen (STN) is a key indicator of soil fertility and quality, and is closely related to land productivity (Franzluebbers and Stuedemann, 2009). As an important part of STN, available

\footnotetext{
${ }^{*}$ Corresponding author: BI Rutian (E-mail: sxndbrt@163.com) Received 2018-03-05; revised 2018-09-25; accepted 2018-10-10

(C) Xinjiang Institute of Ecology and Geography, Chinese Academy of Sciences, Science Press and Springer-Verlag GmbH Germany, part of Springer Nature 2019
} 
nitrogen supplies the necessary macro nutrient for plant growth and leaf photosynthesis (Boussadia et al., 2010). However, excessive nitrogen content in soil is one of the largest contributors of non-point pollution, such as soil acidification, eutrophication, water-quality problems, and even gaseous emissions (Carpenter et al., 1998; Rode et al., 2009; Velthof et al., 2014).

The distribution of STN exhibits spatial variability, which is caused by environmental factors including climate, topography, soil parent material, land use and human activity (Liu et al., 2008; Basso et al., 2016). In addition, the spatial variability of STN is scale-dependent as different factors and processes may operate at different scales and intensities (Hu et al., 2014). Thus, the spatial variability of STN is a function of scale (Lin et al., 2005; Wang et al., 2010). However, recent studies mainly focused on the inherency of spatial variability in STN at a single scale (Momtaz et al., 2009; Jacksonblake et al., 2012). It is essential to exploring the spatial patterns of STN and the efficient strategies for predicting the distribution of STN in the same region at multiple scales.

Traditional methods, such as Pearson's linear analysis, multi-fractal analysis, wavelet analysis and geostatistics, can explore multi-scale spatial relationships between soil properties and influencing factors. For example, the multi-scale spatial relationships between soil physical properties and saturated hydraulic conductivity were examined by multi-fractal analysis (Zeleke and $\mathrm{Si}, 2005)$. Zhu et al. (2016) analyzed the scale-specific relationships between soil available micronutrients and environmental factors at the Fenhe River Basin on the Chinese Loess Plateau by wavelet analysis. These methods assume that the distributions of soil properties and the related processes (soil genetic processes and processes of environmental factors influencing on soil properties) are linear (She et al., 2015). However, soil genetic processes that influence the spatial variability of STN may be nonlinear, because the effect of different processes may not be additive or follow the principle of superposition (Hu et al., 2013). Multivariate empirical mode decomposition (MEMD), proposed by Fleureau et al. (2011), is an extended empirical mode decomposition (EMD) algorithm. Unlike traditional methods, MEMD does not require any assumption about the data. Therefore, it may provide a possibility to analyze the non-stationary and nonlinear processes.

Taiyuan Basin, located in the central and eastern Chinese Loess Plateau and in the middle of Shanxi Province, China, is a typical Cenozoic fault basin. The topography of the basin is characterized as a lower-lying center with a high boundary, and the climate is a normal basin climate with rainy summers, short springs and autumns, dry-cold winters, abundant sunshine hours and large temperature difference between day and night ( $\mathrm{Li}$ et al., 2000). Due to the thick layer of loess capped in the surface of the basin, the soil is susceptible to serious erosion. In addition, mosaic land-use pattern of the basin has led to the spatial distribution of STN to be more nonlinear and irregular (She et al., 2015). Taiyuan Basin is the major agricultural region in Shanxi Province. Precision analysis of the spatial distribution of STN is needed for agriculture management in this basin. With the development of Vis-NIR spectroscopy, the high-quality Vis-NIR spectrum is easily available, which provides inexpensive information of STN. Understanding the multi-scale spatial correlations of Vis-NIR soil spectrum and STN is needed for spatial prediction of STN in Taiyuan Basin.

The multi-scale of soil properties has been previously studied using MEMD ( $\mathrm{Hu}$ and $\mathrm{Si}, 2013$; She et al., 2015), but these studies mainly focused on soil physical properties at small watershed scales, while little is known about the validity of MEMD for the spatial variability of STN at a medium-sized basin scale. The objective of this study was to explore the scale-specific relationships between STN and influencing factors in Taiyuan Basin of the Chinese Loess Plateau using MEMD analysis. Specifically, the dominant scales of the variability in STN were identified at the upstream, midstream and downstream of the basin, and the dominant controls of the influencing factors on STN at the corresponding scales were determined.

\section{Materials and methods}

\subsection{Study area}

Taiyuan Basin $\left(37^{\circ} 00^{\prime}-38^{\circ} 20^{\prime} \mathrm{N}, 111^{\circ} 30^{\prime}-113^{\circ} 00^{\prime} \mathrm{E} ; 700-1000 \mathrm{~m}\right.$ a.s.1.) is located in the central and 
eastern Chinese Loess Plateau, China. The basin is enclosed by hills and mountains and covers an area of $6159 \mathrm{~km}^{2}$. Taiyuan Basin is characterized by a typical semi-arid climate with annual mean temperature of $9.5^{\circ} \mathrm{C}$, mean annual precipitation of $425-520 \mathrm{~mm}$, and mean annual evaporation of $1780 \mathrm{~mm}$. Due to the dust deposition during the Quaternary, the landform in Taiyuan Basin is characterized by a thickly loess-covered layer. The thickness of the loess layer ranges from 50 to $3000 \mathrm{~m}$, and the grain size of the loess generally increases from the center to the margin of the basin (Zhu et al., 2016). Fenhe River, the second largest tributary of the Yellow River, runs through the basin from northeast to southwest. The major soil types are Calcaric Fluvisols and Calcaric Cambisols under alkaline conditions according to the FAO-90 soil classification system (Nachtergaele et al., 2009). The dominant crops in the basin are corn, wheat and millet.

\subsection{Experimental design and data collection}

We divided the basin into three parts according to the direction of Fenhe River and the elevation of the basin: upstream, midstream and downstream. Further, based on remote sensing images and land use types, we established sampling transects 1,2 and 3 along the vertical direction of Fenhe River at the upstream, midstream and downstream part of the basin, respectively (Fig. 1). The transect was around $42 \times 10^{3} \mathrm{~m}$ long for each. The land use types were dominated by cropland and forest land for transects 1 and 2. Specifically, cropland accounted for about $95 \%$ of the total land in the transect, with the main plant species of corn, while forest land accounted for about $5 \%$ of the total land, which was mainly located at the end of the transect. For transect 3, the land use was mainly covered by cropland, with the main crops of corn and the mixture of corn and fruit tree. The specific tillage methods were different for the lands belonging to different owners. Tillage methods included human-powered tillage and mechanical work.

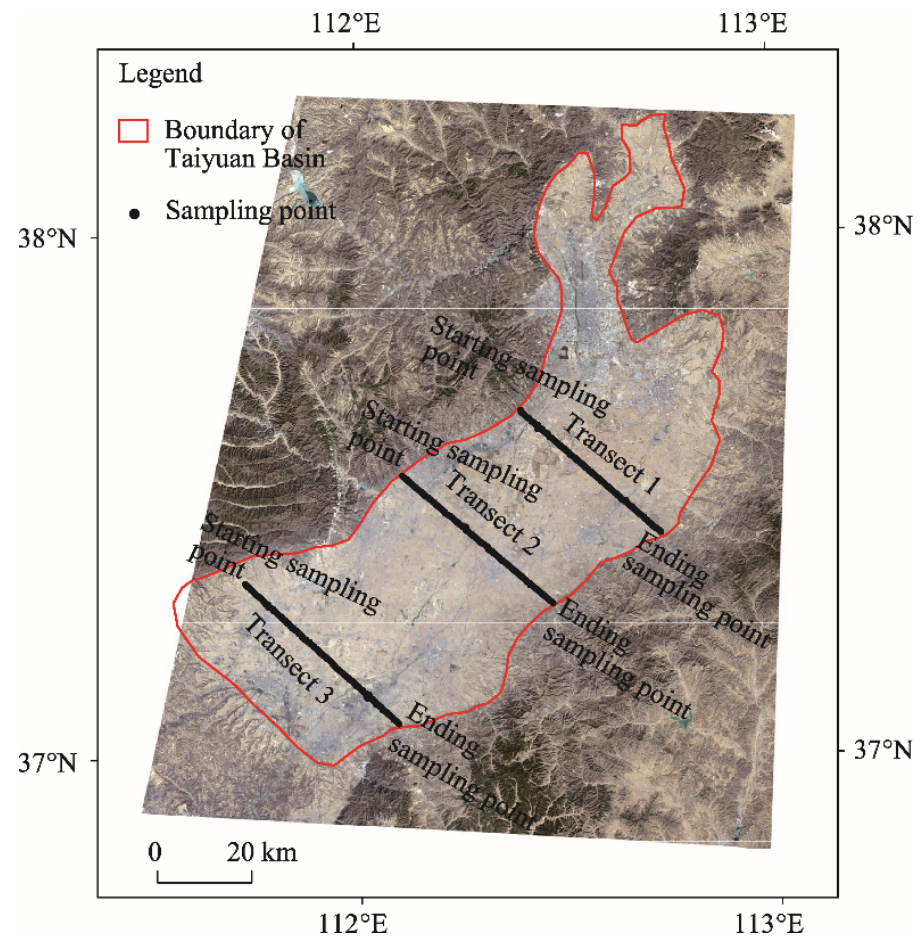

Fig. 1 Distribution of sampling transects and sampling points in the three transects in Taiyuan Basin. Sampling transects 1, 2 and 3 are located at the upstream, midstream and downstream part of the basin, respectively.

A total of 383 soil sampling points was designed in Taiyuan Basin with 121, 128 and 134 points for transects 1, 2 and 3, respectively. The interval between sampling points in each transect is 330 $\mathrm{m}$ and those sampling points are shown in Figure 1. It should be pointed out that if the sampling 
point was located on the non-agricultural land such as buildings or roads, then the nearest point on the agricultural land was used to represent this sampling point. The location of each sampling point was measured by a GPS receiver.

The field investigation was conducted during 12-31 March, 2016. At each sampling point, the undisturbed soil was collected using a metallic core cylinders of $100 \mathrm{~cm}^{3}$ volume $(5 \mathrm{~cm}$ in height and $5 \mathrm{~cm}$ in diameter) in the surface soil layer to determine soil bulk density (BD). BD was calculated after oven-drying the core cylinders at $105^{\circ} \mathrm{C}$ for $24 \mathrm{~h}$ using the dried soil weight and volume of the core cylinder (Hossain et al., 2015). At each sampling point, five soil samples were collected from the surface soil layer of $0-20 \mathrm{~cm}$ and then they were mixed for one sample to further analysis. These samples were air-dried, gently crushed, and passed through a 2-mm sieve. Sub-samples were finely ground to pass through a $0.15-\mathrm{mm}$ sieve for STN measurement. The content of STN was determined by the Kjeldahl method (Bremner and Tabatabai, 1972). Contents of sand $(0.050-2.000 \mathrm{~mm})$, silt $(0.002-0.050 \mathrm{~mm})$ and clay $(<0.002 \mathrm{~mm})$ were determined by the pipette method (Gee and Bauder, 1986). Approximately $30 \mathrm{~g}$ of soil was placed in a soil holder (1.5 $\mathrm{cm}$ in height and $8.0 \mathrm{~cm}$ in diameter) and scanned for the Vis-NIR reflectance spectra by the Vis-NIR spectroscopy of ASD FieldSpec3 (Analytical Spectral Device Inc., Boulder, USA) with the spectral range of $350-2500 \mathrm{~nm}$ and resampled resolution of $1.0 \mathrm{~nm}(1.4 \mathrm{~nm}$ in the range of $350-1000 \mathrm{~nm}$ and $2.0 \mathrm{~nm}$ in the range of $1001-2500 \mathrm{~nm}$ ) under laboratory conditions.

The digital elevation model (DEM) with 30-m resolutions for Taiyuan Basin was downloaded from the Geospatial Data Cloud (http://www.gscloud.cn/sources). It was used to extract topographic indices, including elevation, slope gradient and topographic wetness index (TWI) by ArcGIS 10.5 software (ESRI Inc., USA).

\subsection{Data analysis}

Soil Vis-NIR reflectance spectroscopy is regarded as a promising approach to efficiently obtain soil chemical and physical properties because it is a physically based, rapid, inexpensive, non-destructive and reproducible method (Hu et al., 2015). In this study, the spectra in the range of 400-2450 $\mathrm{nm}$ was transformed using the principal component analysis after removing the noisy portions at 350-400 and 2451-2500 nm in the MATLAB program (Zhou et al., 2016). The first two principal components (PC1 and PC2) of the Vis-NIR soil spectra, which respectively accounted for $89 \%$ and $4 \%$ of the total variance, were selected as the combined environmental factors. The spatial series of STN along with soil physical attributes (BD and sand, silt and clay contents), topographic factors (elevation, slope and TWI) and soil spectral components (PC1 and PC2) constituted the multivariate data series.

The multivariate data series of each of the three sampling transects were decomposed into different IMFs (intrinsic mode functions, IMF1-IMF6) and residues by MEMD method, which was implemented using the MATLAB program developed by Rehman and Mandic (2009). A detailed description about MEMD can be found in studies of Rehman and Mandic (2010) and $\mathrm{Hu}$ and $\mathrm{Si}$ (2013).

The STN at each IMF and residue was predicted from the corresponding IMF and residue of the influencing factors by stepwise multiple linear regression (SMLR). The predicted STN contents at the sampling scale were obtained by adding all the predicted values of STN at each IMF and residue using the following equation:

$$
\mathrm{STN}^{\mathrm{p}}=\sum_{i}^{t} \mathrm{IMF}_{i}^{\mathrm{p}}+\mathrm{R}_{\mathrm{e}}^{\mathrm{p}}
$$

where $\mathrm{STN}^{\mathrm{p}}$ is the predicted STN value at the sampling scale $(\mathrm{g} / \mathrm{kg}) ; t$ is the number of IMF; $\mathrm{IMF}_{i}^{\mathrm{p}}$ is the predicted value of STN at the $i^{\text {th }}$ IMF; and $\mathrm{R}_{\mathrm{e}}^{\mathrm{p}}$ is the predicted value of STN at the residue.

The accuracy of STN prediction was evaluated by three statistical indices, i.e., coefficient of determination $\left(R^{2}\right)$, root mean square error (RMSE) and normalized root mean square error (NRMSE), from the observed and predicted values of STN. The three statistical indices can be calculated using the following equations: 


$$
\begin{gathered}
R^{2}=1-\frac{\sum_{i=1}^{n}\left(Y_{i}^{\mathrm{mea}}-Y_{i}^{\mathrm{pre}}\right)^{2}}{\sum_{i=1}^{n}\left(Y_{i}^{\mathrm{mea}}-\bar{Y}\right)^{2}}, \\
\mathrm{RMSE}=\sqrt{\frac{1}{n} \sum_{i=1}^{n}\left(Y_{i}^{\mathrm{mea}}-Y_{i}^{\mathrm{pre}}\right)^{2}}, \\
\mathrm{NRMSE}=\frac{\mathrm{RMSE}}{\bar{Y}},
\end{gathered}
$$

where $n$ is the number of sampling points of STN; $Y_{i}^{\text {mea }}$ and $Y_{i}^{\text {pre }}$ are the measured and predicted values of STN at the sampling point $i(\mathrm{~g} / \mathrm{kg})$, respectively; and $\bar{Y}$ is the mean of all measured STN contents $(\mathrm{g} / \mathrm{kg})$. The descriptive statistical analysis for STN, Pearson's correlation analysis between STN and influencing factors, SMLR for STN at the sampling scale, each IMF and residue were carried out using SPSS 19.0 software (SPSS Inc., USA).

\section{Results}

\subsection{Statistical analysis of STN with influencing factors at the sampling scale}

The descriptive statistical results of the overall variability of STN in the three sampling transects and in all samples are shown in Table 1. Of the three sampling transects, the mean value of STN in transect 1 was the smallest, while the CV of STN in transect 3 was the lowest. The average elevation was lowest in transect 2, while its CV value was lower in transects 1 and 2 than in transect 3. The CV values of STN, elevation, TWI, silt and clay were similar in transects 1 and 2. Among the three transects, the mean values of PC1 and PC2 were similar, but there were some

\begin{tabular}{|c|c|c|c|c|c|c|c|c|c|c|}
\hline & \multicolumn{2}{|c|}{ STN } & \multicolumn{2}{|c|}{ Elevation } & \multicolumn{2}{|c|}{ Slope } & \multicolumn{2}{|c|}{ TWI } & \multicolumn{2}{|c|}{$\mathrm{BD}$} \\
\hline & $\begin{array}{l}\text { Mean } \\
(\mathrm{g} / \mathrm{kg})\end{array}$ & $\begin{array}{l}\mathrm{CV} \\
(\%)\end{array}$ & $\begin{array}{c}\text { Mean } \\
(\mathrm{m})\end{array}$ & $\begin{array}{l}\mathrm{CV} \\
(\%)\end{array}$ & $\begin{array}{c}\text { Mean } \\
\left({ }^{\circ}\right)\end{array}$ & $\begin{array}{l}\mathrm{CV} \\
(\%)\end{array}$ & Mean & $\begin{array}{l}\mathrm{CV} \\
(\%)\end{array}$ & $\begin{array}{c}\text { Mean } \\
\left(\mathrm{g} / \mathrm{cm}^{3}\right)\end{array}$ & $\begin{array}{l}\mathrm{CV} \\
(\%)\end{array}$ \\
\hline Transect 1 & 1.09 & 27.17 & 769.56 & 3.89 & 3.34 & 80.59 & 0.42 & 241.39 & 1.27 & 11.18 \\
\hline Transect 2 & 1.27 & 27.09 & 743.76 & 2.56 & 2.34 & 95.09 & 0.48 & 241.37 & 1.30 & 9.90 \\
\hline Transect 3 & 1.17 & 22.33 & 753.39 & 9.05 & 2.40 & 74.13 & 0.88 & 181.36 & 1.30 & 8.91 \\
\hline \multirow[t]{3}{*}{ All samples } & 1.18 & 26.26 & 755.28 & 6.11 & 2.68 & 85.38 & 0.60 & 216.93 & 1.29 & 10.01 \\
\hline & \multicolumn{2}{|c|}{ Sand } & \multicolumn{2}{|c|}{ Silt } & \multicolumn{2}{|c|}{ Clay } & \multicolumn{2}{|c|}{ PC1 } & \multicolumn{2}{|c|}{ PC2 } \\
\hline & Mean & $\begin{array}{l}\text { CV } \\
(\%)\end{array}$ & Mean & $\begin{array}{l}\mathrm{CV} \\
(\%)\end{array}$ & Mean & $\begin{array}{l}\mathrm{CV} \\
(\%)\end{array}$ & Mean & $\begin{array}{l}\mathrm{CV} \\
(\%)\end{array}$ & Mean & $\begin{array}{l}\mathrm{CV} \\
(\%)\end{array}$ \\
\hline Transect 1 & 0.33 & 54.36 & 0.39 & 32.18 & 0.28 & 36.25 & 6.39 & 20.56 & 2.74 & 5.77 \\
\hline Transect 2 & 0.36 & 47.67 & 0.40 & 30.97 & 0.25 & 37.99 & 6.34 & 14.35 & 2.23 & 6.47 \\
\hline Transect 3 & 0.24 & 51.37 & 0.47 & 21.28 & 0.30 & 27.23 & 6.03 & 22.25 & 2.56 & 6.40 \\
\hline All samples & 0.30 & 53.64 & 0.42 & 28.55 & 0.27 & 34.00 & 6.25 & 19.41 & 2.50 & 10.37 \\
\hline
\end{tabular}
differences in their $\mathrm{CV}$ values.

Table 1 Descriptive statistics of STN and influencing factors in the three transects and in all samples

Note: STN, soil total nitrogen; TWI, topographic wetness index; BD, bulk density; PC1, the first principal component; PC2, the second principal component; CV, coefficient of variance.

Spatial distributions of STN and influencing factors in the three sampling transects are shown in Figure 2. The distribution of elevation along the three transects was characterized by a bowl-shaped topographic depression, and the range of elevation in transect 3 was obviously larger than those in transects 1 and 2. STN and other influencing factors displayed different distributions compared with elevation in the three transects. The ranges of PC1 were similar among the three transects, while the values of PC2 varied greatly, with the ordering of transect $2<\operatorname{transect} 3<\operatorname{transect} 1$. 

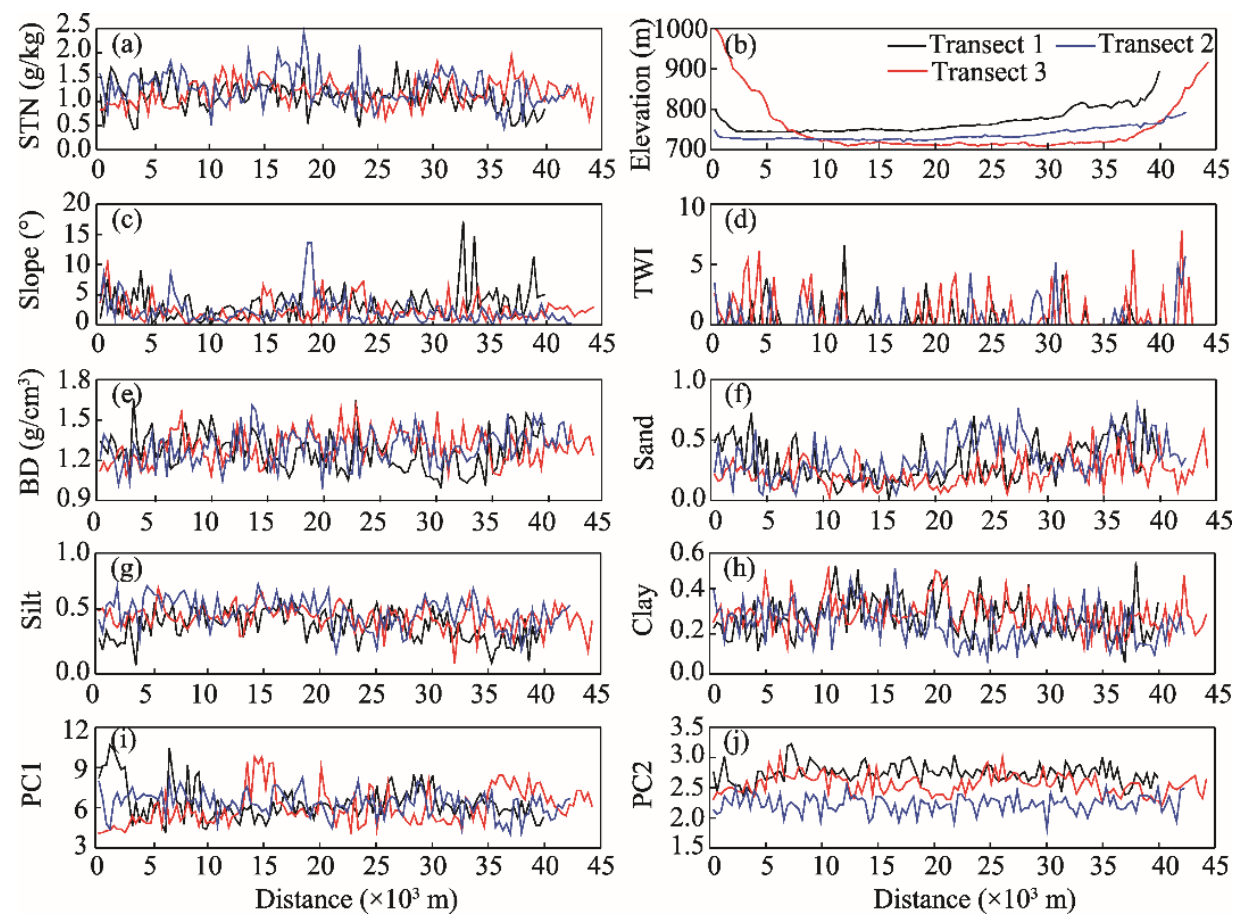

Fig. 2 Spatial distributions of STN (soil total nitrogen) and influencing factors along the three transects at the sampling scales

The correlation coefficients between STN and influencing factors at the sampling scale were determined by Pearson's linear analysis (Table 2). For transect 1, STN was significantly correlated with elevation, $\mathrm{BD}$, sand, silt, clay and $\mathrm{PC} 1$ at $P<0.01$ level and with $\mathrm{PC} 2$ at $P<0.05$ level. There was no significant correlation between STN and TWI $(P>0.05)$. For transect 2, STN was significantly correlated with elevation, slope, BD, sand, silt, clay and $\mathrm{PC} 1$ at $P<0.01$ level. For transect 3, STN was only significantly correlated with elevation and PC1 at $P<0.01$ level, and with sand and silt at $P<0.05$ level. Overall, in the entire basin, STN was significantly related to elevation, soil physical properties (BD, sand, silt and clay), and the combined environmental factors (PC1 and PC2), while significant relationships of STN with slope and TWI were not detected.

Table 2 Correlation coefficients between STN and influencing factors in the three transects and in all samples

\begin{tabular}{cccccccccc}
\hline & \multicolumn{1}{c}{ Influencing factor } \\
\cline { 2 - 10 } & Elevation & Slope & TWI & BD & Sand & Silt & Clay & PC1 & PC2 \\
\hline Transect 1 & $-0.35^{* *}$ & -0.06 & 0.06 & $-0.33^{* *}$ & $-0.50^{* *}$ & $0.49^{* *}$ & $0.27^{* *}$ & $0.36^{* *}$ & $0.22^{*}$ \\
Transect 2 & $-0.25^{* *}$ & $0.23^{* *}$ & 0.02 & $-0.25^{* *}$ & $-0.50^{* *}$ & $0.48^{* *}$ & $0.28^{* *}$ & $0.56^{* *}$ & -0.13 \\
Transect 3 & $-0.34^{* *}$ & -0.14 & 0.11 & -0.09 & $-0.19^{*}$ & $0.22^{*}$ & 0.02 & $0.42^{* *}$ & -0.13 \\
All samples & $-0.31^{* *}$ & -0.01 & 0.06 & $-0.21^{* *}$ & $-0.37^{* *}$ & $0.38^{* *}$ & $0.16^{* *}$ & $0.41^{* *}$ & $-0.20^{* *}$ \\
\hline
\end{tabular}

Note: ${ }^{*}$, significant correlation at $P<0.05$ level; ${ }^{* *}$, significant correlation at $P<0.01$ level.

Predicted equations of STN with one or more influencing factors were obtained using SMLR method, which explained $49 \%, 46 \%$ and $34 \%$ of the total variance in STN for transects 1, 2 and 3, respectively (Table 3). It can be seen that the accuracy of STN prediction in the three transects was generally low, especially for transect 3 .

\subsection{Multi-scale spatial relationships between STN and influencing factors}

The multivariate data series of STN and influencing factors for each transects were decomposed into six different modes of oscillation (IMF1-IMF6) and one residue by MEMD method, which are presented in Figure 3. For each IMF, the number and width of oscillations between STN and 
Table 3 Predicting equations of STN with influencing factors using SMLR for the three transects

\begin{tabular}{cccc}
\hline Transect & Equation & $F$ & $R^{2}$ \\
\hline Transect 1 & $\mathrm{STN}=-0.27+1.21(0.52) \times \mathrm{Clay}+0.71(0.24) \times \mathrm{Silt}+0.11(0.48) \times \mathrm{PC} 1$ & 37.0 & 0.49 \\
Transect 2 & $\mathrm{STN}=0.40+0.03(0.18) \times$ Slope $-0.43(0.16) \times \mathrm{BD}+0.82(0.29) \times \mathrm{Clay}+0.16(0.43) \times \mathrm{PC} 1$ & 26.2 & 0.46 \\
Transect 3 & $\mathrm{STN}=2.50-0.01(0.31) \times$ Elevation $+0.04(0.22) \times \mathrm{TWI}-0.32(0.15) \times$ Sand $+0.07(0.37) \times \mathrm{PC} 1-$ & 13.1 & 0.34 \\
\hline
\end{tabular}

Note: SMLR, stepwise multiple linear regression; $R^{2}$, adjusted coefficient of determination. Numbers in parentheses are the standardized regression coefficients.
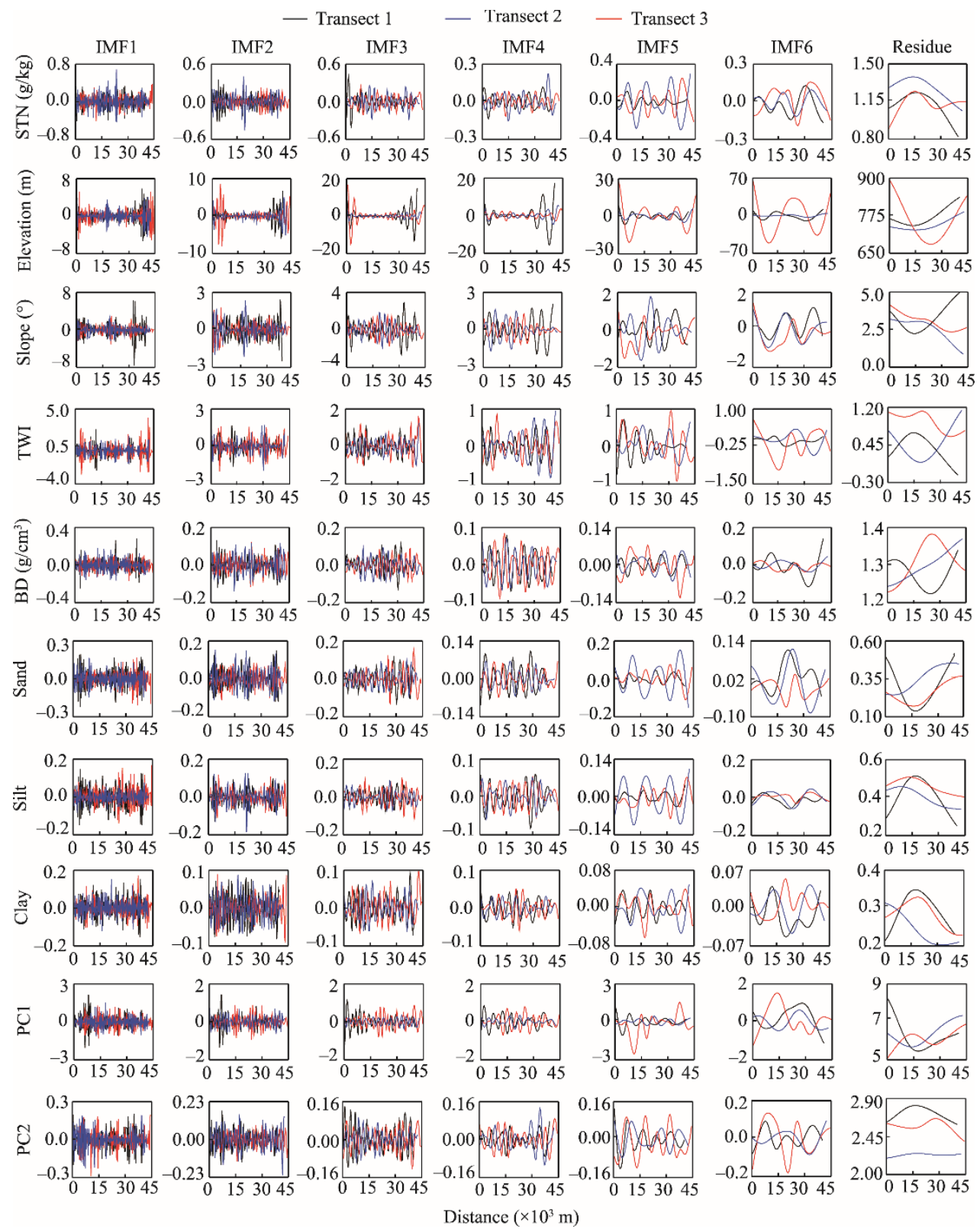

Fig. 3 IMFs (intrinsic mode functions) and residues for STN and influencing factors in the three transects. IMF1IMF6, intrinsic mode function 1-6, respectively.

influencing factors were similar, while for different IMFs, the oscillation modes differed greatly. The scales of STN and influencing factors were identified by Hilbert transform from the oscillatory mode at each IMF, and the mean scales of STN and influencing factors were used to represent the 
scale of each specific IMF (Table 4). The mean scales of IMF1-IMF4 were similar in the three sampling transects, which were around 1000, 1500, 2700 and $4500 \mathrm{~m}$ for IMF1, IMF2, IMF3 and IMF4, respectively. For IMF5, the mean scale was similar in transects 1 and 2 (about $8500 \mathrm{~m}$ ), and the scale in transect 3 was about $5700 \mathrm{~m}$. For IMF6, the mean scale was similar for transects 1 and 3 (approximately 12,500 m), and the mean scale in transect 2 was about $15,500 \mathrm{~m}$. The differences in the identified scale for IMF6 were very large, with the CV values of $15.84 \%, 16.32 \%$ and $23.12 \%$ for transects 1, 2 and 3, respectively.

Table 4 Actual scales of STN and influencing factors for each intrinsic mode function (IMF) in the three transects

\begin{tabular}{|c|c|c|c|c|c|c|c|}
\hline \multirow{2}{*}{ Transect } & \multirow{2}{*}{ Factor } & \multicolumn{6}{|c|}{ Scale (m) } \\
\hline & & IMF1 & IMF2 & IMF3 & IMF4 & IMF5 & IMF6 \\
\hline \multirow{13}{*}{ Transect 1} & STN & 1033 & 1568 & 2712 & 5005 & 8421 & 13,954 \\
\hline & Elevation & 981 & 1595 & 3070 & 5024 & 8074 & 14,539 \\
\hline & Slope & 986 & 1733 & 2717 & 5183 & 7299 & 13,421 \\
\hline & TWI & 1021 & 1642 & 2739 & 4916 & 8244 & 10,394 \\
\hline & $\mathrm{BD}$ & 1015 & 1544 & 2622 & 5288 & 8319 & 14,273 \\
\hline & Sand & 981 & 1540 & 2918 & 5319 & 8451 & 10,373 \\
\hline & Silt & 988 & 1593 & 2845 & 4658 & 8931 & 10,591 \\
\hline & Clay & 963 & 1610 & 3138 & 5742 & 8210 & 10,979 \\
\hline & PC1 & 988 & 1563 & 2756 & 4996 & 9079 & 15,832 \\
\hline & PC2 & 989 & 1598 & 2680 & 4674 & 8379 & 13,869 \\
\hline & Mean & 995 & 1599 & 2819 & 5081 & 8341 & 12,823 \\
\hline & CV (\%) & 2.16 & 3.54 & 6.09 & 6.34 & 5.79 & 15.84 \\
\hline & STN & 922 & 1557 & 2773 & 4369 & 8898 & 15,090 \\
\hline \multirow{10}{*}{ Transect 2} & Elevation & 979 & 1594 & 2996 & 5075 & 9716 & 20,515 \\
\hline & Slope & 911 & 1466 & 2685 & 4812 & 9099 & 16,733 \\
\hline & TWI & 984 & 1421 & 2823 & 4985 & 8766 & 14,414 \\
\hline & BD & 923 & 1426 & 2545 & 4854 & 7410 & 12,244 \\
\hline & Sand & 964 & 1483 & 2866 & 4389 & 9490 & 14,461 \\
\hline & Silt & 1007 & 1444 & 2708 & 4305 & 9480 & 12,271 \\
\hline & Clay & 904 & 1466 & 2876 & 4293 & 8887 & 15,431 \\
\hline & PC1 & 1032 & 1466 & 2648 & 4175 & 7929 & 18,210 \\
\hline & $\mathrm{PC} 2$ & 932 & 1456 & 2519 & 4625 & 8848 & 16,364 \\
\hline & Mean & 956 & 1478 & 2744 & 4588 & 8852 & 15,573 \\
\hline \multirow{13}{*}{ Transect 3} & CV (\%) & 4.60 & 3.76 & 5.53 & 7.06 & 8.03 & 16.32 \\
\hline & STN & 954 & 1444 & 2901 & 3865 & 5880 & 9199 \\
\hline & Elevation & 973 & 1459 & 2742 & 4,856 & 6507 & 15,728 \\
\hline & Slope & 984 & 1433 & 2598 & 4098 & 5149 & 14,738 \\
\hline & TWI & 1079 & 1514 & 2743 & 4470 & 6136 & 15,348 \\
\hline & $\mathrm{BD}$ & 925 & 1567 & 2657 & 4241 & 5748 & 10,081 \\
\hline & Sand & 941 & 1614 & 2414 & 4150 & 5626 & 11,672 \\
\hline & Silt & 964 & 1566 & 2670 & 4482 & 5375 & 10,888 \\
\hline & Clay & 934 & 1567 & 2494 & 3817 & 5576 & 9793 \\
\hline & PC1 & 989 & 1439 & 2614 & 4132 & 5444 & 9534 \\
\hline & PC2 & 975 & 1412 & 2598 & 4355 & 6320 & 16,194 \\
\hline & Mean & 972 & 1502 & 2643 & 4247 & 5716 & 12,317 \\
\hline & CV (\%) & 4.45 & 4.83 & 5.15 & 7.30 & 7.24 & 23.12 \\
\hline
\end{tabular}

Note: IMF1-IMF6, intrinsic mode function 1-6, respectively.

The variance explained by each IMF and residue for STN and influencing factors in the three transects are shown in Table 5. For STN, the total variance explained by the IMF and residue was 
ranked as follows: transect $1<$ transect $2<$ transect 3 , with the percentages of $80.84 \%, 84.29 \%$ and $87.43 \%$ for transects 1, 2 and 3, respectively. The largest variance in STN was IMF1 for transect 1, IMF1 and IMF5 for transect 2, and IMF1 for transect 3. The variance percentage of STN and influencing factors (with the exception of elevation) was mainly contributed by IMF1, while the variance in elevation was mainly contributed by residue. Finally, with the exceptions of sand content in transects 1 and 3 and PC2 in transect 3, the sum of the variance percentage in the six IMFs and the residue for each influencing factor in the three transects were less than $100.00 \%$.

Table 5 Percentage of variance explained by each IMF and residue for STN and influencing factors in the three transects

\begin{tabular}{|c|c|c|c|c|c|c|c|c|c|}
\hline \multirow{2}{*}{ Transect } & \multirow{2}{*}{ Factor } & \multicolumn{8}{|c|}{ Percentage of variance $(\%)$} \\
\hline & & IMF1 & IMF2 & IMF3 & IMF4 & IMF5 & IMF6 & Residue & Total \\
\hline \multirow{11}{*}{ Transect 1} & STN & 27.01 & 13.22 & 13.75 & 3.45 & 1.81 & 7.10 & 14.50 & 80.84 \\
\hline & Elevation & 0.29 & 0.27 & 1.51 & 2.91 & 0.67 & 3.86 & 84.25 & 93.76 \\
\hline & Slope & 42.57 & 8.06 & 12.33 & 11.66 & 4.85 & 3.65 & 8.90 & 92.02 \\
\hline & TWI & 43.15 & 20.62 & 12.72 & 6.20 & 7.04 & 0.67 & 5.00 & 95.40 \\
\hline & $\mathrm{BD}$ & 23.89 & 11.34 & 8.96 & 6.62 & 2.82 & 14.67 & 6.16 & 74.46 \\
\hline & Sand & 22.72 & 9.11 & 8.40 & 6.82 & 1.85 & 5.39 & 46.13 & 100.42 \\
\hline & Silt & 26.11 & 10.39 & 7.61 & 6.08 & 1.70 & 3.25 & 39.73 & 94.87 \\
\hline & Clay & 31.22 & 14.59 & 9.95 & 5.48 & 3.44 & 6.56 & 16.31 & 87.55 \\
\hline & $\mathrm{PC} 1$ & 20.01 & 7.89 & 7.12 & 6.74 & 7.86 & 17.55 & 29.39 & 96.56 \\
\hline & PC2 & 26.26 & 13.36 & 13.25 & 3.92 & 7.70 & 7.75 & 19.03 & 91.27 \\
\hline & STN & 26.48 & 12.10 & 9.53 & 3.67 & 21.69 & 2.97 & 7.85 & 84.29 \\
\hline \multirow{9}{*}{ Transect 2} & Elevation & 0.51 & 0.48 & 0.23 & 0.83 & 2.53 & 0.82 & 79.97 & 85.37 \\
\hline & Slope & 17.52 & 8.14 & 9.64 & 8.08 & 11.30 & 8.59 & 14.85 & 78.12 \\
\hline & TWI & 25.89 & 15.14 & 12.38 & 8.92 & 7.24 & 2.80 & 5.38 & 77.75 \\
\hline & $\mathrm{BD}$ & 34.26 & 12.61 & 10.23 & 10.06 & 5.09 & 0.77 & 9.12 & 82.14 \\
\hline & Sand & 15.66 & 9.29 & 6.60 & 2.72 & 19.19 & 8.58 & 29.24 & 91.28 \\
\hline & Silt & 17.53 & 13.28 & 8.53 & 2.96 & 19.73 & 4.31 & 17.55 & 83.89 \\
\hline & Clay & 27.76 & 12.46 & 11.14 & 5.25 & 6.30 & 7.32 & 20.77 & 91.00 \\
\hline & $\mathrm{PC} 1$ & 27.43 & 14.38 & 15.04 & 6.09 & 8.13 & 1.21 & 6.43 & 78.71 \\
\hline & PC2 & 43.84 & 13.02 & 12.24 & 6.14 & 2.93 & 0.85 & 0.95 & 79.97 \\
\hline \multirow{10}{*}{ Transect 3} & STN & 24.49 & 9.33 & 11.95 & 2.81 & 16.36 & 14.05 & 8.44 & 87.43 \\
\hline & Elevation & 0.05 & 0.09 & 0.32 & 0.05 & 1.86 & 19.19 & 74.39 & 95.95 \\
\hline & Slope & 30.44 & 9.47 & 12.63 & 8.19 & 10.69 & 9.93 & 8.57 & 89.92 \\
\hline & TWI & 39.38 & 15.14 & 9.79 & 4.02 & 5.60 & 7.46 & 1.36 & 82.75 \\
\hline & $\mathrm{BD}$ & 24.84 & 12.91 & 10.08 & 11.32 & 13.66 & 2.70 & 18.09 & 93.60 \\
\hline & Sand & 26.84 & 11.64 & 15.49 & 6.04 & 9.30 & 4.28 & 26.66 & 100.25 \\
\hline & Silt & 27.53 & 15.23 & 17.10 & 6.97 & 10.16 & 2.19 & 13.10 & 92.28 \\
\hline & Clay & 34.11 & 12.72 & 15.26 & 6.50 & 7.16 & 5.89 & 18.15 & 99.79 \\
\hline & $\mathrm{PC} 1$ & 15.26 & 5.52 & 6.53 & 5.88 & 36.88 & 25.67 & 5.20 & 99.94 \\
\hline & PC2 & 22.13 & 6.88 & 7.45 & 6.10 & 14.59 & 28.34 & 14.53 & 100.02 \\
\hline
\end{tabular}

As shown in Table 6, the correlation coefficients between STN and influencing factors for all IMFs and residue based on MEMD varied greatly at different scales. The relationships between STN and influencing factors in transects 1 and 2 were stronger than that in transect 3 . The effect of topographic factors on STN was identical among the three sampling transects, which was significant at a few scales. The correlation of PC1 with STN was similar among the three transects, which was significant at most scales. The relationships between soil physical properties and STN were similar in transects 1 and 2, which were significant at most scales, while the relationships were significant at a few scales for transect 3. Additionally, the correlations between STN and influencing factors were significant for the residue in the three sampling transects. 
Table 6 Correlation coefficients between STN and influencing factors for each IMF and residue based on multivariate empirical mode decomposition (MEMD) in the three transects

\begin{tabular}{|c|c|c|c|c|c|c|c|c|c|c|}
\hline Transect & $\begin{array}{c}\text { IMF/ } \\
\text { Residue }\end{array}$ & Elevation & Slope & TWI & $\mathrm{BD}$ & Sand & Silt & Clay & PC1 & PC2 \\
\hline \multirow{7}{*}{ Transect 1} & IMF1 & -0.02 & $0.22^{*}$ & 0.04 & -0.16 & $-0.48^{* *}$ & $0.39^{* *}$ & $0.28^{* *}$ & 0.17 & 0.17 \\
\hline & IMF2 & 0.12 & -0.06 & -0.17 & $-0.37^{* *}$ & $-0.48^{* *}$ & $0.37^{* *}$ & $0.28^{* * *}$ & $0.53^{* *}$ & -0.14 \\
\hline & IMF3 & $-0.22^{*}$ & 0.05 & $0.30^{* *}$ & $-0.21^{*}$ & $-0.28^{* *}$ & $0.50^{* *}$ & -0.10 & $0.70^{* *}$ & $0.23^{* *}$ \\
\hline & IMF4 & $0.36^{* *}$ & 0.00 & -0.11 & $-0.67^{* *}$ & $-0.47^{* *}$ & $0.23^{*}$ & $0.62^{* *}$ & $0.39^{* *}$ & $0.40^{* *}$ \\
\hline & IMF5 & -0.15 & -0.10 & $0.19^{*}$ & $-0.41^{* *}$ & $-0.62^{* *}$ & $0.40^{* *}$ & $0.43^{* *}$ & $-0.27^{* *}$ & $-0.25^{* *}$ \\
\hline & IMF6 & $-0.59^{* *}$ & -0.10 & $0.18^{*}$ & $-0.76^{* *}$ & -0.17 & $0.39^{* *}$ & -0.08 & $0.42^{* *}$ & -0.13 \\
\hline & Residue & $-0.96^{* *}$ & $-0.98^{* *}$ & $0.98^{* *}$ & $-0.46^{* *}$ & $-0.86^{* *}$ & $0.90^{* *}$ & $0.75^{* *}$ & $-0.31^{* *}$ & $0.90^{* *}$ \\
\hline \multirow{7}{*}{ Transect 2} & IMF1 & -0.04 & $0.18^{*}$ & -0.14 & $-0.26^{* *}$ & $-0.28^{* *}$ & $0.18^{*}$ & $0.19^{*}$ & 0.14 & 0.17 \\
\hline & IMF2 & $0.22^{*}$ & $-0.27^{* *}$ & 0.01 & $-0.23^{* *}$ & $-0.23^{* *}$ & $0.20^{*}$ & 0.10 & $0.29^{* *}$ & 0.16 \\
\hline & IMF3 & $0.40^{* *}$ & -0.11 & 0.02 & $-0.19^{*}$ & $-0.41^{* *}$ & 0.16 & $0.41^{* *}$ & -0.03 & $0.29^{* *}$ \\
\hline & IMF4 & $-0.26^{* *}$ & $0.48^{* *}$ & -0.02 & 0.11 & $-0.22^{*}$ & 0.09 & $0.29^{* *}$ & $-0.23^{* *}$ & -0.17 \\
\hline & IMF5 & 0.07 & $0.47^{* *}$ & $0.49^{* *}$ & $-0.52^{* *}$ & $-0.95^{* *}$ & $0.97^{* *}$ & $0.62^{* *}$ & $0.24^{* *}$ & $-0.78^{* *}$ \\
\hline & IMF6 & $-0.47^{* *}$ & -0.08 & $-0.87^{* *}$ & $-0.41^{* *}$ & $-0.88^{* *}$ & $0.84^{* *}$ & $0.91^{* *}$ & $-0.43^{* *}$ & $-0.66^{* *}$ \\
\hline & Residue & $-1.00^{* *}$ & $0.98^{* *}$ & $-0.89^{* *}$ & $-0.87^{* *}$ & $-0.75^{* *}$ & $0.85^{* *}$ & $0.60^{* *}$ & $-0.97^{* *}$ & $0.19^{*}$ \\
\hline \multirow{7}{*}{ Transect 3} & IMF1 & 0.04 & 0.03 & $0.18^{*}$ & 0.06 & $-0.41^{* *}$ & $0.48^{* *}$ & 0.03 & $0.27^{* *}$ & -0.02 \\
\hline & IMF2 & $-0.23^{* *}$ & -0.05 & 0.13 & $0.35^{* *}$ & $-0.22^{*}$ & $0.28^{* *}$ & -0.06 & 0.11 & -0.05 \\
\hline & IMF3 & 0.06 & 0.00 & $0.60^{* *}$ & -0.14 & -0.04 & -0.01 & 0.07 & $0.25^{* *}$ & $0.21^{*}$ \\
\hline & IMF4 & $-0.26^{* *}$ & 0.07 & $0.74^{* *}$ & -0.16 & $-0.25^{* *}$ & $0.22^{*}$ & 0.09 & $0.24^{* *}$ & $0.36^{* *}$ \\
\hline & IMF5 & $-0.22^{*}$ & -0.16 & $0.32^{* *}$ & $-0.76^{* *}$ & $-0.29^{* *}$ & 0.06 & $0.42^{* *}$ & $0.47^{* *}$ & $-0.69^{* *}$ \\
\hline & IMF6 & $-0.64^{* *}$ & $-0.40^{* *}$ & -0.12 & $-0.49^{* *}$ & $-0.52^{* *}$ & $0.88^{* *}$ & 0.01 & $0.31^{* *}$ & $-0.22^{*}$ \\
\hline & Residue & $-0.52^{* *}$ & $-0.27^{* *}$ & $0.18^{*}$ & $0.31^{* *}$ & $-0.32^{* *}$ & $0.29^{* *}$ & $0.33^{* *}$ & $0.72^{* *}$ & $-0.37^{* *}$ \\
\hline
\end{tabular}

Note: ${ }^{*}$, significant correlation at $P<0.05$ level; ${ }^{* *}$, significant correlation at $P<0.01$ level.

\subsection{STN prediction based on multi-scale spatial relationships of STN and influencing factors}

Based on multi-scale effects of influencing factors on STN, we derived the predicted equations of STN at each scale using SMLR. The results are shown in Table 7. The $R^{2}$ value of all predicted equations ranged from 0.28 to 1.00 , generally increasing from IMF1 to IMF6. STN at the sampling scale was predicted by adding all predicted values of STN at each IMF and residue, and its prediction accuracy is shown in Table 8 . Based on multi-scale spatial relationships between STN and influencing factors from MEMD, we can see that the $R^{2}$ values between measured STN and predicted STN at the sampling scale were $0.82,0.80$ and 0.77 for transects 1,2 and 3 , respectively. They were notably higher than those $(0.49,0.46$ and 0.34 for transects 1,2 and 3 , respectively) derived from the original dataset by SMLR at the sampling scale. The RMSE and NRMSE values for the predicted equations derived by MEMD were lower than those obtained by SMLR.

The correlation coefficients between predicted STN by each IMF (residue) from all influencing factors and measured STN at the sampling scale are shown in Figure 4a. The results showed that IMF1, IMF2 and IMF3 almost contributed equally to the overall prediction of STN in transect 1, IMF1 and IMF5 were the dominant contributors for transect 2, while IMF1 and IMF6 were the main contributors in transect 3. The correlation coefficients between measured STN at the sampling scale and STN predicted by each influencing factor from different IMF scales are shown in Figure 4b. These results showed that sand, silt and PC1 were the main explanatory factors for STN prediction in transect 1 , sand and silt were the dominant explanatory factors in transect 2, while elevation, $\mathrm{BD}$ and $\mathrm{PC} 1$ were the main factors for STN prediction in transect 3.

\section{Discussion}

The spatial distributions of STN and the relationships of STN with influencing factors were scale-dependent. To reveal the scale-specific effects of influencing factors on STN, we analyzed 
Table 7 Predicted equations and regression statistics $\left(F\right.$ value and adjusted $\left.R^{2}\right)$ for STN at each IMF and residue using SMLR based on MEMD

\begin{tabular}{|c|c|c|c|c|}
\hline Transect & $\begin{array}{c}\text { IMF/ } \\
\text { Residue }\end{array}$ & Equation & $F$ & $R^{2}$ \\
\hline \multirow{7}{*}{$\begin{array}{c}\text { Transect } \\
1\end{array}$} & IMF 1 & $\begin{aligned} \mathrm{STN}= & -0.01(0.15) \times \text { Elevation }+1.29(0.54) \times \text { Silt }+0.84(0.31) \times \text { Clay }+0.10(0.37) \times \\
& \mathrm{PC} 1+0.29(0.15) \times \mathrm{PC} 2\end{aligned}$ & 14.4 & 0.39 \\
\hline & IMF 2 & $\begin{aligned} \mathrm{STN}= & -0.01+0.01(0.14) \times \text { Elevation }+0.39(0.17) \times \mathrm{BD}+1.09(0.42) \times \mathrm{Silt}+0.50(0.18) \times \\
& \text { Clay }+0.11(0.38) \times \mathrm{PC} 1-0.31(0.17) \times \mathrm{PC} 2\end{aligned}$ & 19.4 & 0.51 \\
\hline & IMF 3 & $\begin{aligned} \mathrm{STN}= & 0.01+0.01(0.11) \times \text { Elevation }+0.02(0.16) \times \text { Slope }+0.08(0.27) \times \mathrm{TWI}+ \\
& 1.20(0.38) \times \text { Silt }+0.19(0.60) \times \mathrm{PC} 1\end{aligned}$ & 48.6 & 0.68 \\
\hline & IMF 4 & $\begin{aligned} \mathrm{STN}= & 0.01+0.01(0.87) \times \text { Elevation }-0.02(0.27) \times \text { Slope }+0.09(0.44) \times \mathrm{TWI}+ \\
& 0.43(0.36) \times \text { Sand }+1.72(0.74) \times \text { Clay }+0.15(0.94) \times \mathrm{PC} 1-0.63(0.36) \times \mathrm{PC} 2\end{aligned}$ & 56.8 & 0.78 \\
\hline & IMF 5 & $\begin{aligned} \mathrm{STN}= & -0.01-0.13(1.93) \times \text { Slope }-0.28(2.05) \times \mathrm{TWI}-2.88(1.72) \times \mathrm{BD}-2.25(0.94) \times \\
& \text { Silt }+0.71(0.34) \times \text { Clay }-0.14(1.30) \times \mathrm{PC} 1-1.22(1.34) \times \mathrm{PC} 2\end{aligned}$ & 359.5 & 0.96 \\
\hline & IMF 6 & $\begin{aligned} \mathrm{STN}= & 0.01-0.01(0.64) \times \text { Elevation }-0.32(2.11) \times \text { Slope }-0.38(0.44) \times \mathrm{TWI}- \\
& 4.26(2.93) \times \mathrm{BD}-1.85(0.96) \times \text { Sand }-7.98(2.32) \times \text { Silt }-0.36(2.49) \times \mathrm{PC} 1- \\
& 0.46(0.26) \times \mathrm{PC} 2\end{aligned}$ & $43,351.7$ & 1.00 \\
\hline & Residue & $\begin{aligned} \mathrm{STN}= & 9.53-0.26(1.85) \times \mathrm{Slope}-1.26(0.39) \times \mathrm{BD}+0.89(0.33) \times \mathrm{Clay}-0.01(0.05) \times \\
& \mathrm{PC} 1-2.27(1.38) \times \mathrm{PC} 2\end{aligned}$ & $1,418,244.7$ & 1.00 \\
\hline \multirow{7}{*}{$\begin{array}{l}\text { Transect } \\
\quad 2\end{array}$} & IMF 1 & $\begin{aligned} \mathrm{STN}= & 0.05(0.24) \times \mathrm{Slope}-0.66(0.28) \times \mathrm{BD}+0.94(0.27) \times \mathrm{Silt}+1.09(0.30) \times \text { Clay }+ \\
& 0.74(0.34) \times \mathrm{PC} 2\end{aligned}$ & 9.4 & 0.28 \\
\hline & IMF 2 & $\begin{aligned} \mathrm{STN}= & -0.06(0.34) \times \mathrm{Slope}+0.72(0.27) \times \mathrm{Silt}+1.14(0.31) \times \mathrm{Clay}+0.16(0.33) \times \mathrm{PC} 1+ \\
& 0.81(0.41) \times \mathrm{PC} 2\end{aligned}$ & 12.6 & 0.34 \\
\hline & IMF 3 & $\begin{aligned} \mathrm{STN}= & 0.05(0.49) \times \text { Elevation }-0.03(0.28) \times \text { Slope }-0.07(0.31) \times \mathrm{TWI}+0.39(0.19) \times \\
& \mathrm{BD}-1.11(0.51) \times \text { Sand }-0.06(0.12) \times \mathrm{PC} 1+0.88(0.35) \times \mathrm{PC} 2\end{aligned}$ & 17.0 & 0.51 \\
\hline & IMF 4 & $\begin{aligned} \mathrm{STN}= & -0.07(1.49) \times \text { Elevation }+0.06(0.55) \times \text { Slope }+0.25(1.31) \times \mathrm{TWI}+1.12(0.49) \times \\
& \mathrm{BD}-1.52(0.52) \times \text { Silt }+3.25(0.71) \times \text { Clay }+0.20(0.39) \times \mathrm{PC} 1\end{aligned}$ & 53.6 & 0.76 \\
\hline & IMF 5 & $\begin{aligned} \mathrm{STN}= & 0.02(0.21) \times \text { Elevation }+0.05(0.21) \times \text { Slope }+0.19(0.33) \times \mathrm{TWI}+0.86(0.16) \times \\
& \mathrm{BD}+1.56(0.58) \times \text { Silt }-0.62(0.10) \times \text { Clay }-0.19(0.22) \times \mathrm{PC} 1-1.86(0.46) \times \mathrm{PC} 2\end{aligned}$ & $12,296.9$ & 1.00 \\
\hline & IMF 6 & $\begin{aligned} \mathrm{STN}= & -0.01(0.44) \times \text { Elevation }+0.06(0.76) \times \mathrm{Slope}+1.08(0.54) \times \mathrm{BD}+1.78(1.31) \times \\
& \text { Silt }+0.30(0.18) \times \text { Clay }+0.09(0.75) \times \mathrm{PC} 1-0.20(0.20) \times \mathrm{PC} 2\end{aligned}$ & $164,904.5$ & 1.00 \\
\hline & Residue & $\begin{aligned} \mathrm{STN}= & 2.69-0.01(0.33) \times \text { Elevation }+0.02(0.16) \times \text { Slope }-0.14(0.45) \times \mathrm{TWI}+ \\
& 0.46(0.20) \times \text { Clay }-0.12(0.02) \times \mathrm{PC} 2\end{aligned}$ & $57,919,687.8$ & 1.00 \\
\hline \multirow{7}{*}{$\begin{array}{l}\text { Transect } \\
3\end{array}$} & IMF 1 & $\mathrm{STN}=-1.23(0.60) \times$ Sand $-0.94(0.34) \times$ Clay $+0.08(0.31) \times \mathrm{PC} 1-0.40(0.24) \times \mathrm{PC} 2$ & 15.8 & 0.33 \\
\hline & IMF 2 & $\mathrm{STN}=-0.01(0.45) \times$ Elevation $+0.57(0.48) \times$ Silt & 14.0 & 0.28 \\
\hline & IMF 3 & $\mathrm{STN}=0.03(0.18) \times$ Slope $+0.11(0.63) \times \mathrm{TWI}+0.08(0.28) \times \mathrm{PC} 1$ & 34.7 & 0.45 \\
\hline & IMF 4 & $\mathrm{STN}=0.04(0.44) \times$ Slope $+0.13(0.96) \times \mathrm{TWI}-0.16(0.14) \times \mathrm{BD}+0.52(0.31) \times$ Silt & 161.4 & 0.83 \\
\hline & IMF 5 & $\begin{aligned} \mathrm{STN}= & -0.01(0.87) \times \text { Elevation }+0.12(0.63) \times \text { Slope }+0.15(0.55) \times \mathrm{TWI}- \\
& 0.64(0.26) \times \mathrm{BD}+0.89(0.31) \times \text { Sand }-1.17(0.24) \times \text { Clay }-1.80(1.07) \times \mathrm{PC} 2\end{aligned}$ & 288.5 & 0.94 \\
\hline & IMF 6 & $\begin{aligned} \mathrm{STN}= & -0.01(0.75) \times \text { Elevation }+0.02(0.13) \times \text { Slope }+0.09(0.39) \times \mathrm{TWI}- \\
& 3.55(0.69) \times \mathrm{BD}+1.29(0.19) \times \text { Silt }+0.02(0.16) \times \mathrm{PC} 1-0.29(0.25) \times \mathrm{PC} 2\end{aligned}$ & 4751.6 & 1.00 \\
\hline & Residue & $\begin{aligned} \mathrm{STN}= & 3.12+0.01(0.22) \times \text { Elevation }-0.18(1.25) \times \text { Slope }+2.86(1.35) \times \text { Silt }- \\
& 0.04(0.19) \times \mathrm{PC} 1-0.92(0.76) \times \mathrm{PC} 2\end{aligned}$ & $656,059.2$ & 1.00 \\
\hline
\end{tabular}

Note: Numbers in parentheses are the standardized regression coefficients.

Table 8 Statistic indices used to assess the overall prediction accuracy of STN by SMLR and MEMD methods

\begin{tabular}{ccccc}
\hline Method & Transect & RMSE $(\mathrm{g} / \mathrm{kg})$ & NRMSE & $R^{2}$ \\
\hline \multirow{3}{*}{ SMLR } & Transect 1 & 0.21 & 0.18 & 0.49 \\
& Transect 2 & 0.25 & 0.20 & 0.46 \\
& Transect 3 & 0.21 & 0.18 & 0.34 \\
MEMD & Transect 1 & 0.17 & 0.15 & 0.82 \\
& Transect 2 & 0.20 & 0.16 & 0.80 \\
& Transect 3 & 0.17 & 0.14 & 0.77 \\
\hline
\end{tabular}

Note: RMSE, root mean square error; NRMSE, normalized root mean square error.

the relationships between STN and influencing factors at the sampling scale and at the multi-scales in this study. The correlations between STN and influencing factors such as elevation, BD, sand, silt, clay, PC1 and PC2 at the sampling scale implied that the variability of STN at this scale was mainly correlated with $\mathrm{BD}$, the balance of different soil particle sizes, elevation and combined environmental factors of PC1 and PC2. The effects of influencing factors on STN were relatively weak at the downstream than at the upstream and midstream of the basin, and STN at the 

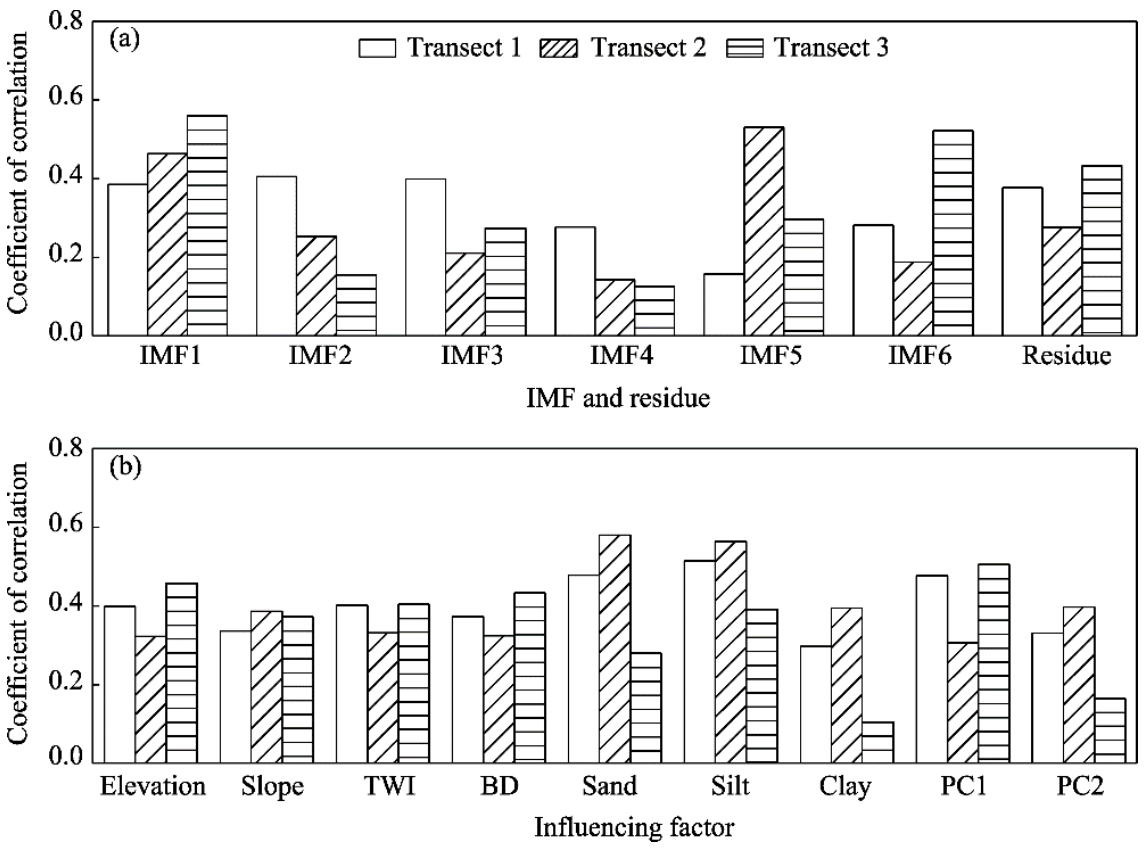

Fig. 4 Correlation coefficients (a) between measured STN and predicted STN by each IMF (or residue) of all influencing factors and (b) between measured STN and predicted STN by each influencing factor of all IMFs (and residue) in the three transects

downstream was only correlated with elevation, sand, silt and PC1, indicating that local processes, such as tillage and biological activities induced perturbation, obscured the other expected relationships so that the effects were found to be non-significant. The least accurate prediction for STN in transect 3 by SMLR might be attributed to the lowest CV among the three transects.

To examine the multi-scale spatial correlations between STN and influencing factors, we decomposed the multivariate data series using MEMD. The MEMD method can project the multivariate data series along different directions in an $n$-dimensional space, align the common scales of the multivariate data, and then group similar scales among different spatial series to represent the actual scales of the related influencing processes. The scales can be identified by the common oscillatory modes using Hilbert transform for all spatial series within the $n$-variate IMF (Rehman and Mandic, 2010). In our study, the scale of each IMF was represented by the mean scales of all spatial series. The scales from IMF1 to IMF4 in the three transects were identical, showing that relative processes might operate at scales of 1000, 1500, 2700 and $4500 \mathrm{~m}$ in Taiyuan Basin, respectively. The scales for IMF5 and IMF6 in the three transects were different and the results implied that the variation in tillage method and soil properties could affect the scale at which STN and influencing factors operated. However, the specific tillage method and land management along the three transects, such as the human-powered tillage or mechanical work, irrigation frequency and amount, and straw returning or not, should be further investigated for the explanation. The differences in the identified scale from environmental factors and STN were larger for IMF6 than for the other IMFs, which indicated that the common scale among STN and influencing factors at the large scale of $>10,000 \mathrm{~m}$ was not obvious for the three transects.

The distributions of variance among different IMFs and residue were different in the three transects. The high variance contributions of IMF1-IMF6 to STN meant that the scales of STN variation were mainly at the identified scales from IMF1 to IMF6 decomposed by MEMD. However, the high variance contribution of residue to elevation might indicate that the scales of dominant variation to STN at the sampling scale were larger than these at the six identified IMF scales, and that a larger sampling transect should be constructed to identify the scales of large variation for elevation. The variance percentages of STN and influencing factors, with the exception of elevation, were mainly contributed by IMF1, which showed that the spatial variations 
in STN and these influencing factors were great at the scale of approximately $1000 \mathrm{~m}$. Moreover, with the exceptions of sand content in transects 1 and 3 and PC2 in transect 3, the sum of the variances of IMF1 to IMF6 and the residue for the highest influencing factors and STN were less than $100.00 \%$ (Table 5), which might be due to the weakness of robust orthogonality between two different IMFs for a given influencing factor (Hu and $\mathrm{Si}, 2013)$.

The multi-scale spatial relationships between STN and influencing factors indicated that sand content negatively while silt content positively affected STN content at almost all IMF scales in the whole basin, and that clay content positively correlated with STN especially at the upstream and midstream of the basin. The results coincide with previous report, which indicated that fine-textured soil tends to store more total nitrogen at regional and sub-regional scales (Li et al., 2016). Elevation was negatively correlated with STN, especially at large scales, which might be attribute to the large variation of elevation at large scales. In a small watershed of Chinese Loess Plateau, Hu et al. (2013) pointed out that the relationship between soil water content and elevation is significant at large scales. Soil BD negatively affected STN at some scales at the downstream of Taiyuan Basin, which were overlooked at the sampling scale. PC1 was correlated with STN at almost all IMF scales, while PC2 was correlated with STN at some IMF scales. Previous studies indicated that the variation of soil Vis-NIR spectra depended on soil components, including STN content (Rossel et al., 2006); therefore, the two principal spectra components of PC1 and PC2 were related to STN in Taiyuan Basin. The correlation between STN and PC1 was positive at the sampling scale in Taiyuan Basin, but the correlation at multi-scales was positive at the upstream and downstream of the basin and negative at the midstream. This might be from the low values of PC1 at the midstream. In addition, the multi-scale spatial correlations between STN and influencing factors in transect 3 were weaker than those in transects 1 and 2, which might be due to the greater variation in tillage methods resulting from the high variation of topography in transect 3 .

In this study, we obtained the predicted equations of STN at multi-scales by SMLR based on MEMD. The increasing trends in the adjusted $R^{2}$ values of STN predicted equations from IMF1 to IMF6 might indicate that when the effects of the selected influencing factors on STN are more dominant at large scales, the predicted equations are more accurate. The prediction of STN at the sampling scale by summing all of the predicted IMFs and residue was more accurate than that by using SMLR directly. Thus, the correlations between STN and influencing factors at the sampling scale did not reveal the complex relationships between them.

The correlation between the overall STN at the sampling scale and at each predicted IMF (residue) or between the overall STN at the sampling scale and the total predicted STN by each influencing factor from different IMF scales was analyzed for STN prediction at the sampling scale. The results indicated that among the different IMF scales decomposed by MEMD, the main contributors for the overall STN prediction were at scales $<3000 \mathrm{~m}$ for transect 1 , at scales around 1000 and $8000 \mathrm{~m}$ for transect 2, and at scales of 1000 and $12,000 \mathrm{~m}$ for transect 3 . This showed that the leading processes influencing STN content in Taiyuan Basin occurred at the small scale around $1000 \mathrm{~m}$. In addition, the predicted residue, which might show larger scales, was significantly correlated with the overall STN prediction. This finding indicated that the processes influencing STN distribution in Taiyuan Basin might also be located at scales $>15,000 \mathrm{~m}$, which could be analyzed from longer sampling transects in future studies. The correlation between the overall STN at the sampling scale and the predicted STN by each influencing factor indicated that soil texture was a dominant explanatory factor in STN prediction at the upstream and midstream of the basin, PC1 played a dominant role at the upstream and downstream, and elevation had an important contribution at the downstream due to its larger variance in transect 3.

\section{Conclusions}

In this study, MEMD analysis was used to investigate the multi-scale spatial relationships between STN and influencing factors in Taiyuan Basin located in the Chinese Loess Plateau. The overall 
multivariate series of STN and influencing factors were decomposed into six IMFs and one residue for each transect. The dominant scales of variances in STN existed in IMF1 at the upstream, IMF1 and IMF5 at the midstream, and IMF1, IMF5 and IMF6 at the downstream. Multi-scale spatial correlation coefficients between STN and influencing factors were less significant at the downstream than at the upstream and midstream, due to the high variation in topography. The prediction of STN at the sampling scale by summing all of the predicted IMFs and residue was more accurate than that by SMLR directly. The leading processes influencing STN contents in the entire basin occurred at IMF1 (scale around $1000 \mathrm{~m}$ ). The influencing factors of sand, silt and PC1 were the main contributors for STN prediction at the upstream, sand and silt were the dominant explanatory factors at the midstream, and elevation, BD and PC1 were the main factors at the downstream of Taiyuan Basin. The results obtained from this study can be used to understand the STN spatial variations and STN predictions in the study area and other similar regions in the world.

\section{Acknowledgements}

This research was financially supported by the Research Project of Shanxi Scholarship Council of China (2017075), the Natural Science foundation for Young Scientists of Shanxi Province (201801D221103) and the Innovation Grant of Shanxi Agricultural University (2017ZZ07). The authors thank Ms. XU Zhen, Ms. WANG Peng and Ms. GUO Ying from Shanxi Agricultural University for their assistance in soil sampling collection and sample analysis. We acknowledge the anonymous reviewers for their helpful comments.

\section{References}

Basso B, Dumont B, Cammarano D, et al. 2016. Environmental and economic benefits of variable rate nitrogen fertilization in a nitrate vulnerable zone. Science of the Total Environment, 545-546: 227-235.

Boussadia O, Steppe K, Zgallai H, et al. 2010. Effects of nitrogen deficiency on leaf photosynthesis, carbohydrate status and biomass production in two olive cultivars 'Meski' and 'Koroneiki'. Scientia Horticulturae, 123(3): 336-342.

Bremner J M, Tabatabai M A. 1972. Use of an ammonia electrode for determination of ammonium in Kjeldahl analysis of soils. Communications in Soil Science and Plant Analysis, 3(2): 159-165.

Carpenter S R, Caraco N F, Correll D L, et al. 1998. Nnonpoint pollution of surface waters with phosphorus and nitrogen. Ecological Applications, 8(3): 559-568.

Fleureau J, Kachenoura A, Albera L, et al. 2011. Multivariate empirical mode decomposition and application to multichannel filtering. Signal Processing, 91(12): 2783-2792.

Franzluebbers A J, Stuedemann J A. 2009. Soil-profile organic carbon and total nitrogen during 12 years of pasture management in the Southern Piedmont USA. Agriculture, Ecosystems \& Environment, 129(1-3): 28-36.

Gee G W, Bauder J W. 1986. Particle-size Analysis. In: Klute A. Methods of Soil Analysis. Part 1. Physical and Mineralogical Methods ( $2^{\text {nd }}$ ed.). Madison: Soil Science Society of America, 383-411.

Hossain M F, Chen W, Zhang Y. 2015. Bulk density of mineral and organic soils in the Canada's arctic and sub-arctic. Information Processing in Agriculture, 2(3-4): 183-190.

Hu K L, Li H, Wang S Y, et al. 2014. Spatial scaling effects on variability of soil organic matter and total nitrogen in suburban Beijing. Geoderma, 226-227: 54-63.

$\mathrm{Hu}$ W, Si B C. 2013a. Soil water prediction based on its scale-specific control using multivariate empirical mode decomposition. Geoderma, 193-194: 180-188.

$\mathrm{Hu}$ W, Biswas A, Si B. 2013b. Application of multivariate empirical mode decomposition for revealing scale-and season-specific time stability of soil water storage. Catena, 113(1): 377-385.

Hu W, Chau H W, Si B C. 2015. Vis-Near IR reflectance spectroscopy for soil organic carbon content measurement in the Canadian Prairies. CLEAN-Soil Air Water, 43(8): 1215-1223.

Jacksonblake L, Helliwell R C, Britton A J, et al. 2012. Controls on soil solution nitrogen along an altitudinal gradient in the Scottish uplands. Science of the Total Environment, 431(5): 100-108.

Li D, Gao G, Lü Y, et al. 2016. Multi-scale variability of soil carbon and nitrogen in the middle reaches of the Heihe River basin, northwestern China. Catena, 137: 328-339.

Li Y, Yang J, Hu X. 2000. Origin of ground fissures in the Shanxi Graben System, Northern China. Engineering Geology, 55(4): 267-275.

Lin H S, Wheeler D, Bell J, et al. 2005. Assessment of soil spatial variability at multiple scales. Ecological Modelling, 182(3-4): 
271-290.

Liu X M, Zhao K L, Xu J M, et al. 2008. Spatial variability of soil organic matter and nutrients in paddy fields at various scales in southeast China. Environmental Geology, 53(5): 1139-1147.

Momtaz H R, Jafarzadeh A A, Torabi H, et al. 2009. An assessment of the variation in soil properties within and between landform in the Amol region, Iran. Geoderma, 149(1-2): 10-18.

Nachtergaele F, van Velthuizen H, Verelst L, et al. 2009. Harmonized world soil database. Food and Agriculture Organization of the United Nations. Rome, Italy and IIASA; Laxenburg, Austria.

Rehman N, Mandic D P. 2009. Qualitative analysis of rotational modes within three-dimensional empirical mode decomposition. In: IEEE International Conference on Acoustics. Washington: IEEE Computer Society, 3449-3452.

Rehman N, Mandic D P. 2010. Multivariate empirical mode decomposition. Proceedings of the Royal Society A, 466(2117): 1291-1302.

Rode M, Thiel E, Franko U, et al. 2009. Impact of selected agricultural management options on the reduction of nitrogen loads in three representative meso scale catchments in central Germany. Science of the Total Environment, 407(11): 3459-3472.

Rossel R A V, Walvoort D J J, McBratney A B, et al. 2006. Visible, near infrared, mid infrared or combined diffuse reflectance spectroscopy for simultaneous assessment of various soil properties. Geoderma, 131(1-2): 59-75.

She D, Zheng J, Shao M A, et al. 2015. Multivariate empirical mode decomposition derived multi-scale spatial relationships between saturated hydraulic conductivity and basic soil properties. CLEAN-Soil Air Water, 43(6): 910-918.

Velthof G L, Lesschen J P, Webb J, et al. 2014. The impact of the Nitrates Directive on nitrogen emissions from agriculture in the EU-27 during 2000-2008. Science of the Total Environment, 468-469: 1225-1233.

Wang D D, Shi X Z, Wang H J, et al. 2010. Scale effect of climate and soil texture on soil organic carbon in the uplands of Northeast China. Pedosphere, 20(4): 525-535.

Zeleke T B, Si B C. 2005. Scaling relationships between saturated hydraulic conductivity and soil physical properties. Soil Science Society of America Journal, 69(6): 1691-1702.

Zhou Y, Biswas A, Ma Z, et al. 2016. Revealing the scale-specific controls of soil organic matter at large scale in Northeast and North China Plain. Geoderma, 271: 71-79.

Zhu $\mathrm{H}, \mathrm{Hu} \mathrm{W}, \mathrm{Bi} \mathrm{R}$, et al. 2016. Scale- and location-specific relationships between soil available micronutrients and environmental factors in the Fen River basin on the Chinese Loess Plateau. Catena, 147: 764-772. 